Theunissen, N.C.M., Tates, K.

Models and theories in studies on educating and counseling children about physical health:

a systematic review.

Patient Education and Counseling: 55, 2004, nr. 3, p. 316-330

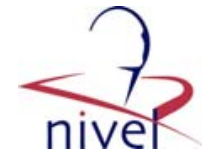

\begin{tabular}{|l|l|}
\hline Postprint Version & 1.0 \\
\hline Journal website & $\underline{\text { http://www.sciencedirect.com/science/journal/07383991 }}$ \\
\hline Pubmed link & $\begin{array}{l}\text { http://www.ncbi.nlm.nih.gov/entrez/query.fcgi?cmd=Retrieve\&db=pubmed\&dop } \\
\text { t=Abstract\&list_uids=15582337\&query_hl=50\&itool=pubmed_docsum }\end{array}$ \\
\hline DOI & $\underline{\underline{10.1016 / j . p e c .2004 .08 .016}}$
\end{tabular}

REVIEW

\title{
Models and theories in studies on educating and counseling children about physical health: a systematic review
}

NiCOLET C.M. THEUNISSEN ${ }^{\mathrm{A}, \mathrm{C}, *}$, KIEK TATES ${ }^{\mathrm{B}, \mathrm{C}}$

${ }^{a}$ Department of Training and Instruction, Learning Technologies, TNO Human Factors, P.O. Box 23, 3769 ZG Soesterberg, The Netherlands

${ }^{b}$ Netherlands Institute of Health Services Research (NIVEL), PO Box 1568, 3500 BN Utrecht, The Netherlands

${ }^{\mathrm{c}}$ Research Institute for Psychology and Health, Utrecht, The Netherlands

* Corresponding author. Tel.: +31 346356 454; fax: +31 346353 977. E-mail address:

nicolet@ntheunissen.nl (N.C.M. Theunissen).

\begin{abstract}
The aim of this review is to gain a comprehensive view on the theories and models referred to in studies on educating and counseling children about physical health. A computer search was conducted using PubMed Medline, and Silverplatter Webspirs Psycinfo. Original studies, reviews, and theoretical papers published between 1992-2003 were included. The review presents the results of the 35 studies in which the majority of the subjects were between 0 and 12 years of age. A classification system is proposed that helped grouping the models, and the interrelationship between this classification and the characteristics of the reviewed studies is explored. The classification could function as an introductory guide and help to select appropriate theories and models when defining future research agenda's. The results of this review may attribute to the refinement of the theoretical underpinning of child education and counseling in physical health.
\end{abstract}

\section{INTRODUCTION}

Child-centered health education and counseling interventions are important, because they have the potential to promote healthy lifestyle patterns and may diminish healthcompromising behaviors. Furthermore, health-related behaviors in childhood can establish lifestyle patterns that will protect or harm participants into their adult years (the socalled tracking phenomenon) [1]. For instance, it is difficult to change health-risk behaviors (e.g., smoking, physical inactivity) once established in childhood. In addition, it is suggested that the risk factors for adult chronic disease begin in childhood [1].

Although child-centered health care and health education are increasingly being put in the center of attention, less attention has been paid to the theoretical underpinning of these interventions. A good theory helps to understand the mechanisms and explains the factors that are amenable to change [2]. This leaves the question how one can recognize a 'good' theory. 
One option is to use theories or models which have been used in health education in general [2-4]. For instance, the well-known Health Belief Model. This model predicts that people are more motivated to take health actions if the perceived threat of the disease is high and if the benefits of behavior are thought to outweigh the barriers [3,5]. Another well-known theory is the Transtheoretical Stages of Change Model, according to which intentional change is a gradual movement through specific but non-linear stages, from not intending to change to sustaining change and resist temptation to relapse. Interventions to facilitate change will be most effective if they are tailored to the motivational stage an individual has reached [6,7]. Both aforementioned models imply that motivation or intention determines (health) behavior. Other well-known models emphasize the influence of the social surrounding on (health) behavior, for instance the Social Cognitive Theory. This model points to a complex interaction among the environment, person, and behavior [8]. The Social Cognitive Theory was not specifically developed for health education, but has been widely used in this context.

The difference between generic and health specific models is another aspect one has to consider when choosing a theory or model. Generic educational models generally have as an advantage that they are thoroughly tested, validated and proven useful, although this is done in other domains than that of health. On the other hand, the experiences in other educational domains can be used as inspiration within the health domain. Health-related models have the advantage that they are more sensitive to the psychosocial elements that are most relevant in changing health behavior.

In spite of the potential usefulness of models applied in health education in general, these models have mainly been developed for adults. Child health education interventions should take into account that children develop. Developmental psychology may provide useful health education models, for instance, the Cognitive Development Theory, developed by Piaget [9]. It has the central assumption that misconceptions, confusion, and partial understanding are consequences of cognitive immaturity, which partly can be overcome by advancement in maturation. Vygotsky, a contemporary of Piaget, added that socio-cultural environment is considered important in knowledge construction, which is emphasized by neo-Piagetians [9]. Bibace and Walsh adapted the resulting stage theory to health education, by mapping children's cognitive understanding of illness concepts, and thus the level of explanations that might appropriately be given to children [10].

A final way of selecting a model or theory is using the ones that related studies already have applied. However, this pragmatic approach prevents that models are chosen on their own merits. It remains uncertain if popular theories are the best choice for the given research question.

With this review, we choose to gain a comprehensive view on the state of the art in this important, though understudied, field of research. Theory-based interventions may facilitate the identification of those factors most likely to be effective, enabling the design of more effective interventions. In this way, the results of this review may help to select appropriate theories and models when defining future research on child health education and counseling. In reviewing the literature, we confine our search to child-centered health education. Following the definition of patient-centeredness [11], health education must be considered child-centered either when the study explicitly incorporates children's expectations, or when attempts have been made to activate the child to take an active part in the management of their health and illness.

Presuming that there are many different kinds of models used in health education, a classification will be needed in organizing the analysis and discussion in our review study. To our knowledge, there is no real classification of models on educating and counseling children in physical health available yet. Therefore, the primary objective of this review is to gain a comprehensive view on the theories and models referred to in studies on educating and counseling children about physical health. A secondary aim is to group these models into a meaningful classification, and to explore the interrelationship between this classification and the characteristics of the reviewed studies.

\section{DATA COLLECTION}

We conducted a computer search using the internet data bases PubMed Medline (1992-2003) and Silverplatter Webspirs Psycinfo (1992-2003). To identify education and counseling studies search terms like communication, counseling, education, health promotion or prevention were used. To find studies about health, we used search terms like health, patient, physician, practitioner, doctor, clinician, or pediatrician. To include models, terms like models, theories or concepts were included. 
All terms were translated into the databases' corresponding Thesaurus-based keywords (MESH terms, Major descriptors if applicable). It appeared that, there was little agreement in the databases's definitions of keywords. Perhaps this accounts for the little overlap in hits we found. The search resulted in 1748 hits (1386 in Pubmed and 362 in Psycinfo). After merging the doubles, 1742 references of publications remained.

The following criteria for selecting studies were used: original studies as well as reviews or theoretical papers were included. The majority of the subjects had to be between the ages of 0 and 18 years and the publication had to mention an educational model or theory. The objective should be educating or counseling children about physical health, therefore, studies about mental retardation or with psychiatric patients were excluded. Searches were limited to publications in English. On the basis of the information of the abstracts of these 1742 references, only 190 met the selection criteria.

Consensus was reached about the final selection of references. A reprint of these papers was obtained from scientific libraries. In spite of good library facilities in The Netherlands, 18 publications were not available and therefore were excluded. Seven of them were book chapters, five were dissertations, and six were journal articles.

The remaining 172 papers were studied in full by both researchers in order to conclude whether they fitted the selection criteria. Although these publications all seemed to meet the selection criteria according to the information obtained from the database, finally 117 fully met the selection criteria. The search terms used, resulted in many hits that appeared not to be useful in the end. For example, in spite of limitation to studies about children between 0 and 18 years of age, often it was not the children, who were educated, but their parents, teachers or health care providers. Many publications had to be excluded because the 'model' referred to was, for instance, a statistical model and not the model for education or counseling. Nevertheless, in retrospect it was not possible to use better search term when conducting the literature search.

The result of 117 studies is an unusual number for a review and we, therefore, decided to split the review study in two parts. This first paper focuses on the 35 studies in which children were an important subject group (ages between 0 and 12 years). The remaining studies focusing on adolescents (in which the majority of subjects were between the ages of 12 and 18) are described elsewhere [12]. Both the list of the precise search terms used in this review and the list of the excluded publications can be obtained from the authors.

\section{RESULTS}

\subsection{Classification of the models referred to in the reviewed publications}

We could identify three model categories as organizing devices, that is: Developmental, Motivational, and Social. Developmental models imply that children develop biologically, cognitively, emotionally and socially. Motivational models imply that motivation or intention determines (health) behavior, although other additional factors may be necessary to predict behavior. Social models may include motivational elements but they emphasize the influence of the social surrounding on (health) behavior. Furthermore, each model category could be subdivided into two levels: theoretical and practical.

At the left hand side in Table 1 the theoretical models are given. These are models or theories that attempt to explain why people behave as they do in relation to their health. The right hand side covers the practice models, which is the translation of theoretical ideas into a conceptual framework for practice. They describe the conditions within which interventions can be made to be effective. Although practice models share concepts with their theoretical counterparts, they do not necessarily share the same relations between concepts.

\section{[ TABLE 1 ]}

In addition to this main classification system, two extra sub-classifications appeared relevant when grouping the models. The first one is a distinction based on what concepts are additionally emphasized by the models, irrespective of the main model categories developmental, motivational and social. We found Cognition, Psychosocial, and Risk/ protective factors as main focuses. Of course, this is not a 
complete set of focuses and they are not mutually exclusive. Nevertheless, it appeared helpful in grouping the models, and therefore we added these focuses as sub-titles in Table 1. The second subclassification is based on the distinction between Health-related and Generic models. In Table 1 these categories are indicated with 'hr' and 'g' respectively. In the next paragraphs, the result of the classification is given. All models referred to in the reviewed publications are grouped within our classification system. In the Appendix A, we provide a brief description of all models. It should be noted that publications often referred to more than one model and therefore the relationship between model and publication is not one-to-one.

Thirteen publications (see Table 1) referred to a Developmental Theoretical Model. Main concepts are differences between ages, changes in time, and often stages of change. Cognitive Development Theories are leading in developmental psychology and were, not surprisingly, referred to in nine of the reviewed publications. An example of a theory with a psychosocial focus is the Humanistic Model applied by Richardson [44]. Developmentally appropriate techniques, such as puppetry and roleplaying, may assist children with end-stage renal disease to enhance self-appreciation and self-respect.

Six publications (see Table 1) referred to a Developmental Practice Model that translates the theoretical ideas about the importance of developmental aspects into a conceptual framework for practice. For instance, Tieffenberg et al. [41] used a child-centered training model for children with chronic illness based on children's expectations and thereby respecting child autonomy. This intervention based on play techniques, led to better selfmanagement skills, higher self-reliance, and appropriate preventive techniques, thereby improving the children's functioning and quality of life. It is notable that none of these Developmental Practice Models build on their theoretical counterparts, although they share concepts.

Nine publications referred to a Motivational Theoretical Model. Main concepts are: beliefs, cognitions and attitudes about health and behavior, self-efficacy, and motivation or intentions to perform a behavior. As can be seen in Table 1, the focus Cognition is over represented in this model category: seven publications discussed how cognition influences motivation or behavior. For example, Claar et al. [31] showed the utility of an appraisal-based model in understanding children's experiences with medical procedures. They examined the influence of cognitive appraisals on anticipatory anxiety, procedural distress, and postprocedural evaluations of children undergoing an invasive medical procedure.

Six publications referred to Motivational Practice Models that translated the theoretical ideas about the importance of motivational and behavioral aspects into a conceptual framework for practice. All practice motivational models appeared to be cognition-based. An example of this model category is the Theoretical Model of Exercise Habit Formation [23]. Aarts et al. based this model on concepts of the Theory of Reasoned Action. Expanding on the idea that habits are the result of automated cognitive processes, the importance of continued repetition and more practice in the formation of health-enhancing exercise habits was stressed.

Twenty-one publications referred to Social Theoretical Models. Main concepts are social norms, environment, social influences, reinforcement, self-efficacy and social modeling. Most referred to were the Social Cognitive Theory [8] and Social Learning Theory [17]. In her meticulously described study based on Social Learning Theory, Lieberman [47] showed that interactive games can improve children's health self-efficacy when they rehearse specific health behaviors in a simulated environment and then experience successful consequences as a result of their own decisions.

Five publications referred to Social Practice Models that translated the theoretical ideas about the importance of social aspects into a conceptual framework for practice. An example of this model category is the Youth Empowerment and Support Program (YES-P) [15]. Moody et al. developed this intervention using key concepts from the Resiliency Model and the Developmental Asset Framework to decrease drug use and strengthen connections to school in at-risk youth living in high-risk environments. The study showed that the social context could mediate the effect of high-risk environments on individual development.

\subsection{Characteristics of the reviewed studies}

After our classification of theories and models, we will now change perspective to the characteristics of the 35 studies under review. All papers were published between 1993 and 2003-an average amount of three per year of publication, with two peaks up in $1997(N=5)$ and $2000(N=6)$. The 
greater majority of the studies were conducted in the USA; only six publications had another country of origin [23,29,33,35,41,43].

The screening of the objectives addressed in the publications yielded three main topics, illustrated by the horizontal subdivision in Table 2: (1) prevention education (18 studies promoting healthy behavior and discouraging health-compromising behavior); (2) providing and understanding information (nine studies targeting explaining and understanding health and illness concepts or information regarding medical procedures); and (3) self-management of chronic conditions (eight studies targeting on selfmanagement skills and education programs for chronically ill children). The distribution of studies on prevention education is skewed towards the more recent years. Most studies on providing and understanding information were conducted during the middle and late nineties, whereas the interest for research on chronic conditions applied for the whole period.

\section{[ TABLE 2 ]}

Half of the eighteen publications on prevention education aimed at motivating children to develop healthy behaviors, by promoting dietary changes $[13,21,24]$ and physical activity $[23,26]$, and by stimulating protective life-style behaviors $[14,17,18,20,28,30]$. The other nine studies took a riskfocused approach by discouraging health-compromising behavior in youth, such as drug and alcohol abuse [15,16,19,27], smoking behavior [29] and general healthcompromising behaviors [22,25]. All studies on prevention education targeted healthy or at-risk children [13,15,17,19,30]. The nine studies focusing on providing and understanding information targeted on children's understanding and conceptualizations of health and illness [33,36], and the design and provision of effective healthrelated communication [31,32,34,35,37-39]. Four publications focused on hospitalized children $[31,33,38,39]$, and the remaining studies on this topic targeted healthy children. The objective of the eight studies on children with a chronic condition was to describe and test interventions promoting the selfmanagement skills of these chronically ill children [41,42,46,47], and the proposal of education programs [43-45]. Table 2 shows that most studies targeted children with asthma, whether or not in combination with another chronic condition such as epilepsy or diabetes.

Sixteen non-empirical publications considered reviewing the literature or proposing a model as their main study aim, leaving nineteen empirical studies primarily aiming at testing a model or identification of determinants, whether or not in combination with a model proposal or a literature review. The study aim of the 35 selected publications differed somewhat over the three types of topics (see Table 2). Most publications on prevention education were empirical studies. Eleven out of the 18 studies primarily aimed at testing a model or at identifying the determinants of the model proposed. Five out of the nine studies on providing and understanding information were non-empirical and focused on reviewing the literature or model proposal. The eight publications on chronic conditions were equally split up in non-empirical and empirical studies.

Although our review focused on studies aiming at educating as well as counseling children about physical health, all but three studies included in the review solely focused at health education. Of these three, two publication targeted both health education and counseling [38,46], and only one study explicitly aimed at counseling children [30].

In sum, wecan conclude that the publications on prevention education were mainly empirical studies from the recent years, focused on healthy or at-risk children, primarily with the aim of model testing. Most publications on providing and understanding information were published in the middle and late nineties, focused on both healthy and non-healthy children, and mainly aimed at reviewing the literature or proposing a model. Finally, publications on chronic conditions were conducted during the whole reviewed period, only included non-healthy children, and equally divided their attention to nonempirical and empirical study aims.

\subsection{Characteristics of the studies in relation to the model classification}

In Fig. 1, for each model category, the amount of models referred to within one of the three main topics is given, weighted by the amount of publications within each topic. In the interpretation of this figure, one has to take into account that the amount of models publications refer to, does not provide information about the weight of each model within a publication. Often publications referred to more 
than one model (and therefore the percentages in the figures can exceed 100\%), but described or used only one. Fig. 1 shows that publications with providing and understanding information as main topic primarily referred to Developmental Theoretical Models and did not refer to Social Theoretical or Practice Models. Furthermore, publications targeting providing and understanding information did hardly refer to any practice model, except for Developmental Practice Models. Studies focusing on self-management of chronic conditions or on prevention education primarily referred to Social Theoretical Models. The relationship between topic and the three focuses Cognition, Psychosocial and Risk/protection, is illustrated in Fig. 2. Again, the amount of focuses publications refer to does not provide information about the weight of each focus within a publication. It is noticeable that publications targeting self-management of chronic conditions did only use Cognition as focus. The other two main topics, information and prevention education, both focused on Cognition and Psychosocial and less to Risk/ protection.

\section{[ FIGURE 1-2 ]}

Table 2 shows the relationship between the source of each model and the model category. Threequarter of the publications with self-management of chronic conditions as topic, referred to a previously described model (code 'pre') or models (code 'vari'), whereas the other topics fifty-fifty referred to newly created models (code 'new' or 'int.new') or previously described models.

Publications presenting a new integrative model (code 'int.new') indicated that the authors wanted to combine theoretical insights from more than one model ( 10 out of these 11 publications integrated models from different categories). This was the case in $39 \%$ of the prevention publications, in $25 \%$ of the chronic condition publications and in $22 \%$ of the information publications.

On the basis of these results, we were able to describe a model profile for the three main topics separately. Publications targeting prevention education, were oriented towards Social Theoretical Models (but also referred to other theoretical and practice models). They used a cognition and a psychosocial focus (and sometimes a risk/protection focus), and they most frequently integrated insights from different model and focus categories. Publications focusing on providing and understanding information mainly referred to Developmental Theoretical Models with a cognition focus (although a focus on psychosocial or risk/protection was used as well). They did seldom refer to practice models and showed little signs of integrating insights from different model categories. Publications targeting self-management of chronic conditions were oriented towards Social Theoretical Models (but referred to other models as well). Their focus was solely on cognition, consequently, those studies that integrated insights from different model categories, did not integrate different focuses.

\section{DISCUSSION AND CONCLUSIONS}

\subsection{Classification of theories and models}

To our knowledge, this is the first overarching review focusing on theories and models referred to in studies on educating and counseling children about physical health. In this review, a classification system was proposed that helped grouping the models referred to in the retrieved literature. Six model categories were distinguished: Developmental Theoretical, Developmental Practice, Motivational Theoretical, Motivational Practice, Social Theoretical, and Social Practice. This classification provides an overview of the current state of affairs concerning the theoretical underpinning of child health education research.

We found that a substantial number of publications did not provide sufficient detail on the theoretical foundation of the study, or insufficiently made explicit the link between the proposed intervention and its theoretical underpinning. As such it was not always evident which components of the model were actually used in the interventions. In our view, studies claiming a theoretical basis should pay much more attention to good reporting and high quality description of the models underlying health education interventions.

The presented model classification distinguished models into various categories, which is considered helpful in analyzing the theoretical state of art in educating and counseling children about physical 
health. We consider the classification potentially useful for other target groups as well, and therefore, the classification will be applied to studies targeting adolescents [12]. However, by stressing the differences between models, it is somewhat neglected that on a conceptual level there is a strong affinity between them. Social Models may include motivational elements, Developmental Models may include motivation as stimuli for learning, and Motivational Models may recognize the importance of social surrounding. Consider for instance, the Self-efficacy Theory [16]. This theory stresses the influence of self-efficacy on the motivation for (health) behavioral changes, and was therefore placed within the category Motivational Theoretical Models. The concept self-efficacy is introduced by Bandura [8] and it has become a key variable within various theories, like for instance the Social Learning Theory and Social Cognitive Theory $[43,47,48]$. These latter two theories were placed within the category Social Theoretical Model. The fact that a quarter of the publications made use of new integrative models, emphasizes the importance of each of the presented categories. Rather than making a choice for one of the categories, we would, therefore, suggest considering combinations. However, before starting to create new integrative models, it is necessary to conduct research that pits various well described theoretical and practice models against each other as competing explanations. This is the only way to eliminate those models that have less explanatory power and to refine the successful ones [24].

A new facet in our model classification system is the differentiation between theoretical and practice models. The education and counseling reality is obstinate and therefore theoretical ideas are in need for some translation before they can be used in health education practice.

Practice models can be helpful in this regard, but even practice models will have to be directly linked to their theoretical origin to exceed a common sense step-by-step plan. A valuable tool to facilitate this step from theoretical model to a practice model is Intervention Mapping; a systematic approach to match theoretical methods and empirical evidence to practical strategies and creative delivery systems [49]. In turn, the resulting practice models need to be tested and refined as well.

\subsection{Classification of theories and models in relation to characteristics reviewed studies}

We were able to formulate model profiles for each main topic separately. This yielded meaningful information about which models are frequently referred to, and what focuses appeared to be dominant in relation to the topic under study. We limited our search to publications that explicitly referred to a model or theory. It is therefore unclear whether the studies reviewed are representative for health education and counseling studies with children in general. For instance, why is it that the greater majority of the reviewed studies were conducted in the USA? Are USA authors more modeloriented, or is it that they publish more in general about health education and counseling studies with children? The same questions go for the relatively large group of publications about asthma within the topic chronic conditions. The finding that all but three selected publications focused on health education rather than on counseling, might be the result of our decision to restrict the search to the field of physical health. Subsequent studies will have to explore our premise that, by also including studies on mental health, more publications focusing on counseling children about physical health will show up.

The scope of our review did not allow pronouncing upon the quality of the studies reviewed, or about the effectiveness of the interventions described. Similarly, we could not go into the details of the outcomes targeted in the selected publications. Nevertheless, apart from the theoretical basis and the content of health education interventions, future research should reflect on the surplus value of using instrumental strategies that are attractive for children. Interactive media have shown to be effective in motivating reluctant learners and in attracting them to subjects they would ordinarily avoid [47]. Three of the reviewed studies showed that theoretical models for educating or counseling children can effectively be used with new media such as video's [21], or interactive multimedia computer games $[42,47]$. Future studies need to identify which models are best suited to which behaviors, and whether certain delivery devices are more appropriate for different health behaviors.

\subsection{Educating and counseling children in physical health: child-centered or not?}

Nowadays, it is commonly accepted that children have the fundamental right to participate in health care decisions and communication according to their age and maturity, rather than being passive recipients of care [50,51]. A strong argument in favor of child-centered health care is that especially 
Theunissen, N.C.M., Tates, K.

Models and theories in studies on educating and counseling children about physical health: a systematic review.

Patient Education and Counseling: 55, 2004, nr. 3, p. 316-330

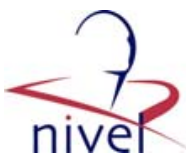

by means of active participation, children can develop responsibility for their own health, and may become competent consumers of health care [52].

Health education and counseling for adults is considered a challenging, though complicated process. This task becomes increasingly arduous when health education targets children, because of the processes of change and development in this reference group [34]. Given this, we expected developmental models to play a prominent role in selected studies on educating children in physical health. Therefore, the proposed classification includes Developmental Models as a distinguishing category. It appeared that in a large group of the reviewed studies referrers to a developmental model was absent, even in a publication included in our review that focused on behavioral theories in educational interventions for children with asthma [40]. Nevertheless, many studies emphasized the importance of taking development into account, although they seldom referred to a developmental model $[24,38]$. It is significant in this regard, that studies with the topic prevention education were the numeric best represented group, but they largely neglected developmental models. To our opinion, every study on educating and counseling children by definition should include a developmental perspective, irrespective of the aim or topic.

The finding that the type of focus was biased towards a cognitive one deserves some further consideration. It is increasingly becoming clear that health education involving only information transfer might be ineffective. Indicative in this regard, is Whaley's conclusion that research concerning explaining illness and disease-related information to children should focus on understanding what children want to know, rather than what health providers want them to know [53]. This plea for an active child role in the management of their health care is in line with studies emphasizing that children's communicative, cognitive, and social competences should not be underestimated in this regard [54-56]. Future health education research should more explicitly include a child-centered perspective, since only by means of active participation children can develop responsibility for their own health [52].

\subsection{Practice implications}

In line with the well-known adage 'There is nothing as practical as a good theory', the findings of this review may lead to a number of implications for medical practice and for health promoting activities aiming at educating and counseling children about physical health. Within the framework of evidence-based medicine, theory-based research is an important step in the development of effective interventions.

The proposed classification of theories and models allows for a comparison of the prevailing theoretical paradigms in child health care and education. In addition, since the classification has a broad scope and covers a wide range of topics and types of focus, the findings are accessible from various angles. As such, this classification may function as an introductory guide and helps to select appropriate theories and models when defining future research agenda's. We, therefore, hope that the results of this review may attribute to the refinement of the theoretical underpinning of child education and counseling in physical health. 
Theunissen, N.C.M., Tates, K.

Models and theories in studies on educating and counseling children about physical health: a systematic review.

Patient Education and Counseling: 55, 2004, nr. 3, p. 316-330

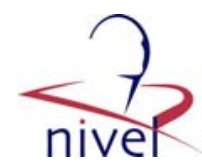

\section{TABLES AND FIGURES}

Table 1

Classification of models referred to in the reviewed publications

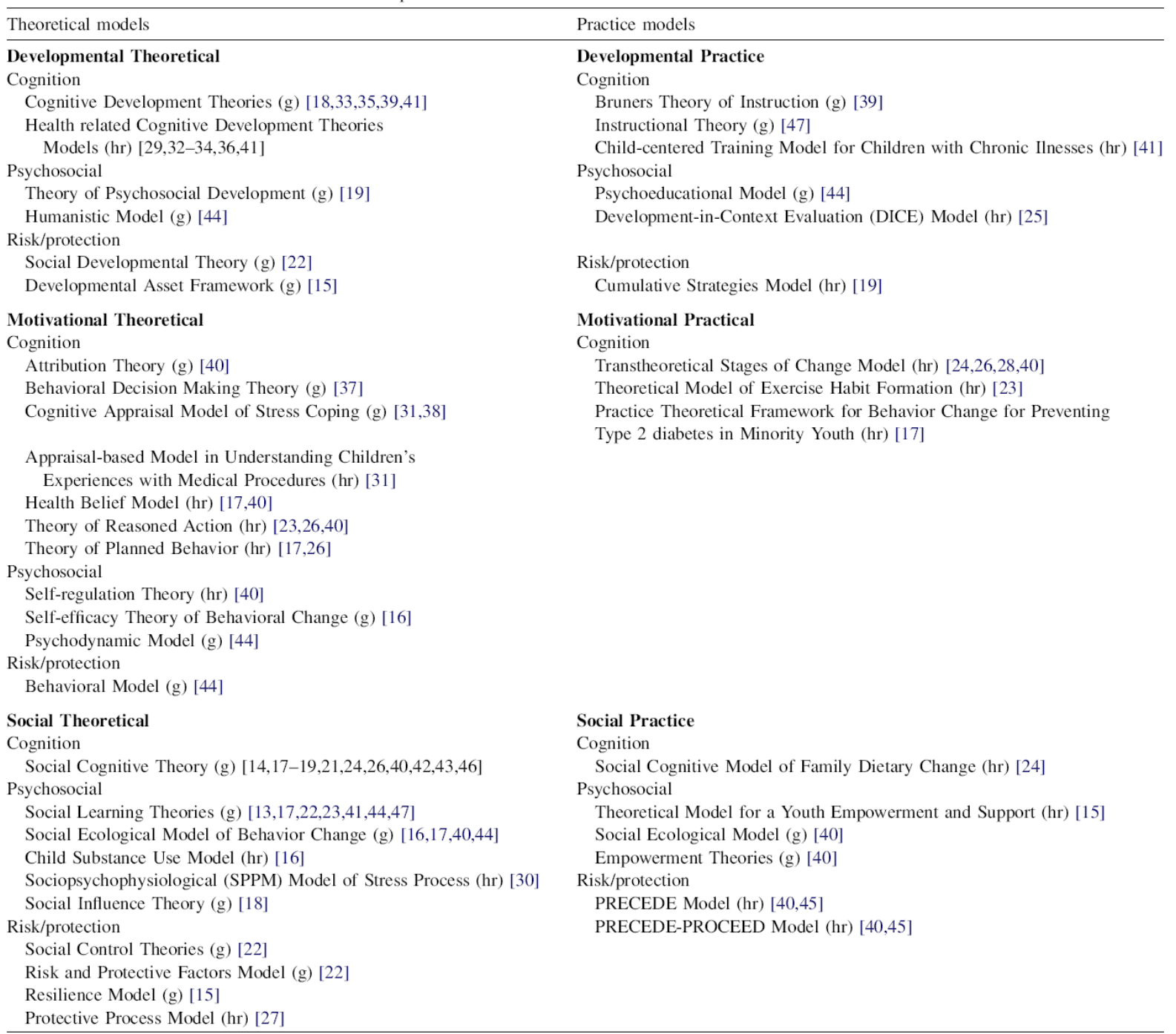


Theunissen, N.C.M., Tates, K.

Models and theories in studies on educating and counseling children about physical health: a systematic review.

Patient Education and Counseling: 55, 2004, nr. 3, p. 316-330
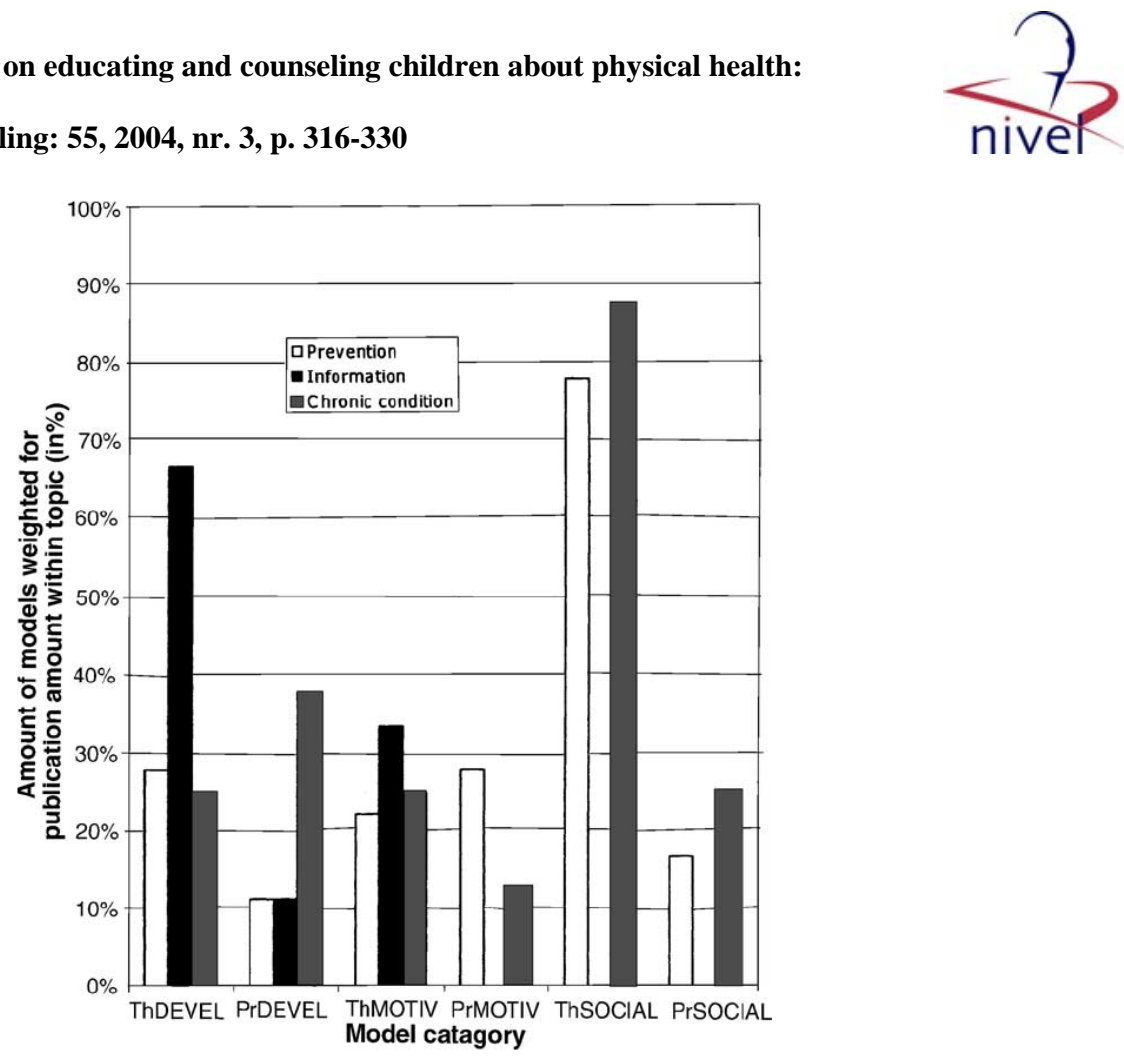

Fig. 1. Relationship between topic and occurrence of model categories within publications. Each publication could refer to more than one mode category; therefore, percentages could exceed $100 \% . \mathrm{Th}=$ theoretical model, $\mathrm{Pr}=$ practice model, $\mathrm{DEVEL}=$ developmental, MOTIV $=$ motivational, and SOCIAL $=$ social

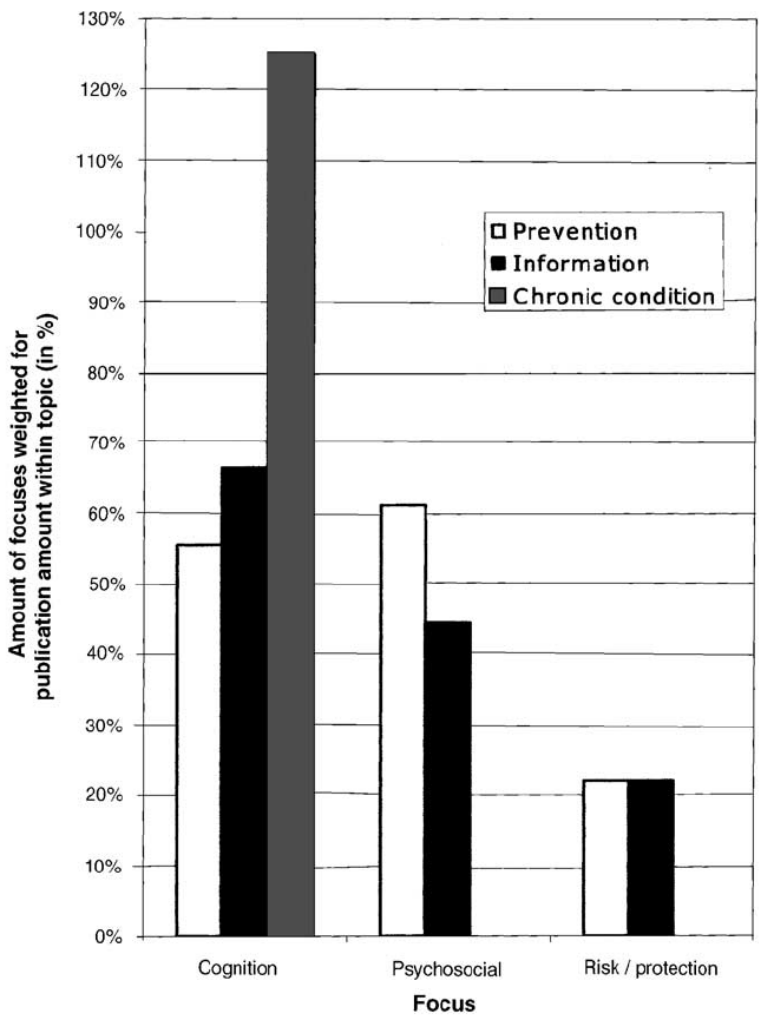

Fig. 2. Relationship between topic and occurrence of focus categories within publications. Each publication could refer to more than one focus; therefore, percentages could exceed $100 \%$. 
Theunissen, N.C.M., Tates, K.

Models and theories in studies on educating and counseling children about physical health:

a systematic review.

Patient Education and Counseling: 55, 2004, nr. 3, p. 316-330

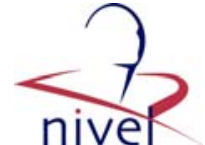

Table 2

Characteristics of the reviewed publications

\begin{tabular}{|c|c|c|c|c|c|c|}
\hline Reference no. & First author + publication year & Topic & Subject characteristics & Study aim & Model (category + focus $)^{\mathrm{a}}$ & Model source ${ }^{b}$ \\
\hline \multicolumn{7}{|l|}{ Prevention } \\
\hline & Stevens, 2003 & $\begin{array}{l}\text { Physical activity } \\
\text { and nutrition }\end{array}$ & $\begin{array}{l}\text { American-Indian } \\
\text { children at-risk for } \\
\text { obesity, age } 8-11\end{array}$ & Test intervention & ThSOCIAL(psysoc) & pre \\
\hline [15] & Moody, 2003 & Alcohol and drugs & $\begin{array}{l}\text { At-risk youth in high-risk } \\
\text { environment, age } 10-12\end{array}$ & $\begin{array}{l}\text { Model proposal + test } \\
\text { model + identification } \\
\text { determinants }\end{array}$ & $\begin{array}{l}\text { ThDEVEL(risk), ThSOCIAL(risk), } \\
\text { PrSOCIAL(psysoc) }\end{array}$ & int.new \\
\hline [16] & Finke, 2002 & Alcohol and drugs & Healthy children age $8-12$ & $\begin{array}{l}\text { Model } \\
\text { proposal + identification } \\
\text { determinants }\end{array}$ & ThMOTIV(psysoc), ThSOCIAL(psysoc) & int.new \\
\hline [17] & Burnet, 2002 & Diabetes & High-risk minority youth & Review + model proposal & $\begin{array}{l}\text { ThMOTIV }(\operatorname{cog} n), \text { PrMOTIV }(\operatorname{cog} n), \\
\text { ThSOCIAL }(\operatorname{cog} n), \text { ThSOCIAL }(\text { psysoc) }\end{array}$ & int.new \\
\hline [18] & Schonfield, 2001 & Cancer prevention & $\begin{array}{l}\text { Healthy children age } 5-11 \\
\text { (mean age } 7,9 \text { ) }\end{array}$ & Test intervention & $\begin{array}{l}\text { ThDEVEL(cogn), ThSOCIAL }(\operatorname{cogn}) \text {, } \\
\text { ThSOCIAL(psysoc) }\end{array}$ & pre \\
\hline [19] & Horn, 2000 & Drug abuse prevention & $\begin{array}{l}\text { At-risk children affected } \\
\text { by familial alcohol abuse, age } 8-9\end{array}$ & Model proposal + test model & $\begin{array}{l}\text { ThDEVEL(psysoc), PrDEVEL(risk), } \\
\text { ThSOCIAL(cogn), }\end{array}$ & int.new \\
\hline [20] & Stanken, 2000 & Helmet use & $\begin{array}{l}\text { Healthy children and } \\
\text { adolescents, age } 5-15\end{array}$ & Review + model proposal & PrSOCIAL(risk) & pre \\
\hline [21] & Baranowski, 2000 & Nutrition & Healthy children age 9-11 & Test intervention & ThSOCIAL $(\operatorname{cog} n)$ & pre \\
\hline [23] & Aarts, 1997 & $\begin{array}{l}\text { Physical exercise } \\
\text { habit formation }\end{array}$ & Healthy children & Model proposal & $\begin{array}{l}\text { ThMOTIV }(\operatorname{cogn}), \text { PrMOTIV }(\operatorname{cogn}), \\
\text { ThSOCIAL(psysoc) }\end{array}$ & int.new \\
\hline [24] & Baranowski, 1997 & Nutrition & Healthy children and adolescents & Review + model proposal & $\begin{array}{l}\text { PrMOTIV }(\operatorname{cog} n) \text {, ThSOCIAL }(\operatorname{cog} n) \text {, } \\
\text { PrSOCIAL }(\operatorname{cog} n),\end{array}$ & int.new \\
\hline [25] & Lerner, 1997 & $\begin{array}{l}\text { Health-compromising } \\
\text { behaviors }\end{array}$ & Healthy children + pre-adolescents & Model proposal & $\operatorname{PrDEVEL}(\mathrm{psysoc})$ & new \\
\hline [26] & Craig, 1996 & Physical activity & $\begin{array}{l}\text { Healthy children } \\
\text { (age group } 8-9 \text { and 12-13) }\end{array}$ & Identification determinants & $\begin{array}{l}\text { ThMOTIV }(\operatorname{cog} n), \text { PrMOTIV }(\operatorname{cog} n), \\
\text { ThSOCIAL }(\operatorname{cog} n)\end{array}$ & pre \\
\hline [27] & Spoth, 1996 & Alcohol & Healthy children, age 11-13 & $\begin{array}{l}\text { Model proposal + test } \\
\text { model + identification } \\
\text { determinants }\end{array}$ & ThSOCIAL(psysoc) & new \\
\hline [28] & Rossi, 1995 & Sun exposure & Healthy children and adolescents & Model proposal & PrMOTIV $(\operatorname{cog} n)$ & pre \\
\hline [29] & Santi, 1994 & Smoking prevention & Healthy children age $11-13$ & Identification determinants & ThDEVEL $(\operatorname{cog} n)$ & pre \\
\hline [30] & Livingston, 1993 & Stress-management & At-risk young Black Americans & Model proposal & ThSOCIAL(psysoc) & pre \\
\hline \multicolumn{7}{|l|}{ Information } \\
\hline [31] & Claar, 2002 & Preprocedural information & $\begin{array}{l}\text { Children undergoing } \\
\text { esophagogastroduodenoscopy } \\
\text { (EGD), age } 8-17\end{array}$ & Model proposal + test model & ThMOTIV $(\operatorname{cog} n)$ & new \\
\hline
\end{tabular}

This is a NIVEL certified Post Print, more info at http://www.nivel.eu 
Theunissen, N.C.M., Tates, K.

Models and theories in studies on educating and counseling children about physical health:

a systematic review.

Patient Education and Counseling: 55, 2004, nr. 3, p. 316-330

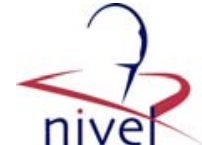

\begin{tabular}{|c|c|c|c|c|c|c|}
\hline Reference no. & First author + publication year & Topic & Subject characteristics & Study aim & Model (category + focus) $)^{a}$ & Model source ${ }^{b}$ \\
\hline [33] & Rushforth, 1999 & $\begin{array}{l}\text { Children's understanding } \\
\text { of health and illness } \\
\text { concepts }\end{array}$ & $\begin{array}{l}\text { Hospitalized, school-aged } \\
\text { children'n }\end{array}$ & Review & ThDEVEL(cogn) & vari \\
\hline [34] & Whaley, 1999 & Explaining illness to children & Healthy children & Model proposal & ThDEVEL(cogn) & pre \\
\hline [35] & Whitener, 1998 & $\begin{array}{l}\text { Design health messages for } \\
\text { children }\end{array}$ & Healthy, school-aged children & Model proposal & ThDEVEL(cogn) & new \\
\hline [36] & Maieron, 1996 & $\begin{array}{l}\text { Illness conceptualizations } \\
\text { about AIDS }\end{array}$ & $\begin{array}{l}\text { Healthy children, age } 9-13,9 \\
\text { (mean age } 11,4)\end{array}$ & Identification determinants & ThDEVEL $(\operatorname{cog} n)$ & pre \\
\hline [37] & Tinsley, 1995 & $\begin{array}{l}\text { Health-related decision } \\
\text { making }\end{array}$ & $\begin{array}{l}\text { Healthy children (age 9-12) } \\
\text { and adolescents (age 14-17) }\end{array}$ & Identification determinants & ThMOTIV(cogn) & int.new \\
\hline [38] & Campbell, 1995 & $\begin{array}{l}\text { Surgical information children } \\
\text { undergoing cardiac surgery }\end{array}$ & $\begin{array}{l}\text { Children (age } 4-12 \text {, mean age } 7 \text { ) } \\
\text { with congenital heart disease } \\
\text { and scheduled for cardiac surgery }\end{array}$ & Test + compare interventions & ThMOTIV $(\operatorname{cog} n)$ & pre \\
\hline [39] & Biddinger, 1993 & Preprocedural teaching & Hospitalized children & Review + model proposal & ThDEVEL $(\operatorname{cog} n)$, PrDEVEL $(\operatorname{cog} n)$ & int.new \\
\hline \multicolumn{7}{|c|}{ Chronic Conditions } \\
\hline [40] & Clark, 2003 & Asthma & Children with asthma & Review & $\begin{array}{l}\text { ThMOTIV(cogn), ThMOTIV(psysoc), } \\
\text { PrMOTIV(cogn), ThSOCIAL (cogn), } \\
\text { ThSOCIAL(psysoc), PrSOCIAL(psysoc), } \\
\text { PrSOCIAL(risk) }\end{array}$ & vari \\
\hline [41] & Tieffenberg, 2000 & $\begin{array}{l}\text { Asthma and epilepsy } \\
\text { self-management }\end{array}$ & $\begin{array}{l}\text { Spanish-speaking children } \\
\text { with severe } \\
\text { asthma and epilepsy, age 6-15 }\end{array}$ & Test model & $\begin{array}{l}\text { ThDEVEL }(\operatorname{cog} n), \operatorname{PrDEVEL}(\operatorname{cog} n) \\
\text { ThSOCIAL(psysoc) }\end{array}$ & int.new \\
\hline [42] & Bartolomew, 2000 & Asthma & $\begin{array}{l}\text { Children and adolescents } \\
\text { with asthma, } \\
\text { age } 7-17 \text { (mean age 11,5) }\end{array}$ & Test model & ThSOCIAL $(\operatorname{cog} n)$ & pre \\
\hline [43] & McGhan, 1998 & Asthma & Children (age 7-12) with asthma & Model proposal & ThSOCIAL $(\operatorname{cog} n)$ & pre \\
\hline [44] & Richardson, 1997 & Renal disease & $\begin{array}{l}\text { Children with end stage renal } \\
\text { disease }\end{array}$ & description intervention & $\begin{array}{l}\text { ThDEVEL(psysoc), PrDEVEL(psysoc), } \\
\text { ThMOTIV(psysoc), ThMOTIV(risk), } \\
\text { ThSOCIAL(psysoc), }\end{array}$ & vari \\
\hline [45] & Bartholomew, 1994 & Juvenile rheumatoid arthritis & $\begin{array}{l}\text { Preschool + school-age children } \\
\text { with Juvenile rheumatoid Arthritis }\end{array}$ & Model proposal & PrSOCIAL(risk) & pre \\
\hline [46] & Parcel, 1994 & Cystic fibrosis & $\begin{array}{l}\text { Children with cystic fibrosis } \\
\text { (age } 0-18 \text {, mean age } 8,6 \text { ) and their } \\
\text { primary caregivers }\end{array}$ & $\begin{array}{l}\text { Test model + identification } \\
\text { determinants }\end{array}$ & ThSOCIAL(cogn) & pre \\
\hline [47] & Lieberman, 2001 & $\begin{array}{l}\text { Asthma and diabetes } \\
\text { self-management }+ \text { smoking } \\
\text { prevention }\end{array}$ & $\begin{array}{l}\text { Children and adolescents with } \\
\text { asthma or diabetes, age 6-16 }\end{array}$ & Model proposal + test model & PrDEVEL(cogn), ThSOCIAL(psysoc) & int.new \\
\hline
\end{tabular}

\footnotetext{
${ }^{\mathrm{a}} \mathrm{Th}=$ theoretical model, $\mathrm{Pr}=$ practice model, $\mathrm{DEVEL}=$ developmental, $\mathrm{MOTIV}=$ motivational, SOCIAL $=$ social; $(\operatorname{cogn})=\operatorname{cognition}$

focus; $($ psysoc) $=$ psychosocial focus, $($ risk $)=$ risk/protection focus.

${ }^{\mathrm{b}}$ Pre $=$ previously described model, vari $=$ various pre-existing models, not integrated, new = new model based on pre-existing models, int.new $=$ integrative new model based on pre-existing models.
} 


\section{APPENDIX A. DESCRIPTION OF THE THEORETICAL AND PRACTICE MODELS REFERRED TO IN THE REVIEWED PUBLICATIONS}

\section{(in alphabetical order)}

1. Appraisal-based Model in Understanding Children's Experiences with Medical Procedures [31] An adjustment of the Cognitive Appraisal Model of Stress Coping to children and medical experiences [31].

2. Attribution Theory [40] Describes how causal explanations influence health behavior [40].

3. Behavioral Decision Making Theory [37] Assesses how individuals get information from their environment about various alternative behaviors, and how they process and weight such information to select one behavior over another [37].

4. Behavioral Model [16,44] People behave the way they do because their behaviors may be increased by positive or negative reinforcers, and decreased by punishment [44].

5. Bruners Theory of Instruction [39] Identifies three consecutive cognitive stages that can be used for instruction [39].

6. Child Substance Use Model [16] Examines the relationships between a child's alcohol or drug use, self-esteem, family climate, family and peer drug abuse and the child's selfefficacy [16].

7. Child-centered Training Model for Children with Chronic Illnesses [41] By learning about the alternatives from which they can choose, children acquire tools to model their behavior in agreement with their health [41].

8. Cognitive Appraisal Model of Stress Coping [31,38] To understand individual differences in response to a stressor, appraisals of that stressor's significance and impact on well-being must be examined [31].

9. Cognitive Development Theories [18,33,35,39,41] Children achieve more understanding when instruction is adapted to cognitive developmental stage (age ranges not necessarily corresponding with chronological age). Socio-cultural environment is considered important in knowledge construction [9,33,35].

10. Cumulative Strategies Model [19] Addresses psychological, behavioral and cognitive risk factors at each level of development. It is designed to develop and implement appropriate prevention interventions for high-risk children. [19].

11. Developmental Asset Framework [15] Emphasizes the importance of protective factors (or assets) which can be external (e.g., relationships, parental support) or internal (competencies and values) [15].

12. Development-in-Context Evaluation (DICE) Model [25] A pragmatic model to link youth, families and the larger community together in health prevention [25].

13. Empowerment Theories [40] Referred to by a reviewed publication that did not provide a description [40].

14. Health Belief Model $[17,40]$ It predicts that the likelihood of action is increased if the perceived threat of the disease is high and if the benefits of behavior are thought to outweigh the barriers $[3,5]$.

15. Health Related Cognitive Development Theories Models [29,32-34,36,41] The stages defined by the Cognitive Development Theories adapted to health education by mapping children's cognitive understanding of illness concepts [10,29].

16. Humanistic Model [44] The goal of humans is to develop their individualities and achieve self-actualization. Children will maximize their potential when adults accept them and guide them in the socialization process [44].

17. Instructional Theory [47] Referred to by a reviewed publication that did not provide a description [47].

18. Practical Theoretical Framework for Behavior Change for Preventing Type 2 diabetes in Minority Youth [17] Synthesizes elements many theories and attempts to address environmental influences on behavior as well as intrapersonal determinants [17]. 
19. PRECEDE Model [40,45] An acronym for Predisposing, Reinforcing and Enabling Causes in Educational Diagnosis and Evaluation. Used for planning safety programs and consists of four process phases (from assessing quality of life, to identifying enabling factors [45].

20. PRECEDE-PROCEED Model [20] Starts with the four phases from the PRECEDE model and adds five evaluation phases [20].

21. Protective Process Model [27] Mastery-esteem, pro-social peer affiliations, and affective relationship with parents, protectively influence older children's tendency to abstain form alcohol use [27].

22. Psychodynamic Model [44] Explains behavior through an analysis of internal processes using three ego states, the Parent, the Child and the Adult (not related to actual age). Children have to be taught to use the last state in health decision making [44].

23. Psychoeducational Model [44] Cognitive as well as affective processes are in continuous interaction [44].

24. Resilience Model [15] Posits two concepts: resiliency and protective factors like positive relationships, as the building blocks to such resiliency [15].

25. Risk and protective factors model [22] When protective factors are absent or week, the negative impact of risk on health-compromising behavior is present [22].

26. Self-efficacy Theory of Behavioral Change [16] Stresses the influence of self-efficacy on the motivation for (health) behavioral changes [16].

27. Self-regulation Theory [40] People create their own personal models of illness, or illness representations, which guide the appraisal of and coping with health threat. Processing occurs both at a cognitive and an emotional level [57].

28. Social Cognitive Model of Family Dietary Change [24] The way family members relate to each other can affect knowledge about dietary behaviors and dietary change [24].

29. Social Cognitive Theory [14,17-19,21,24,26,40,42,43,46] Individuals are not just controlled by environmental and social influences, nor do solely inner or personal forces drive them. Instead, it points to a complex interaction among the environment, person, and behavior $[8,43]$.

30. Social Control Theories [22] Specifies the importance of establishing social bonds and attachments to protect against negative health outcomes caused by delinquency [22].

31. Social Developmental Theory [22] According to their age, children may be exposed to different risk or protective factors, and they may react differently to these factors [22].

32. Social Ecological Model [40] Was mentioned as an example of a theory that is a conceptual framework for practice, but no description was provided [40].

33. Social Ecological Model of Behavior Change [16,17,40,44] Persons are an inseparable part of their social environment. Context affects behavior and environmental conditions elicit certain responses $[17,44]$.

34. Social Influence Theory [18] Referred to by a reviewed publication that did not provide a description [18].

35. Social Learning Theories $[13,17,22,23,41,44,47]$ Learning occurs by observing others who serve as a model for the person's behavior. Three aspects are important: outcome expectation, self-efficacy, and valuation of the perceived consequences of the behavior change $[17,47]$.

36. Socio-psycho-physiological (SPPM) Model of Stress Process [30] Explains the stress process and possible health outcome over time, considering the interaction of individuals with their wider society [30].

37. Theoretical Model for a Youth Empowerment and Support [15] The social context can mediate the effects of high-risk environments on individual development [15].

38. Theoretical Model of Exercise Habit Formation [23] Initiation of exercise is largely determined by deliberate decision making. With continued repetition and more practice, a habit no longer needs to be guided by reasoned considerations because it is automated [23].

39. Theory of Planned Behavior [17,26] An extension of the Theory of Reasoned Action, adding perceived behavioral control and perceived barriers [26,58,59]. 
40. Theory of Psychosocial Development [19] Personality develops in eight stages, each characterized by a distinctive conflict (e.g., learning to be competent) that the individual must resolve. Through the resolution of the conflict at each stage, people acquire new psychosocial skills $[9,19]$.

41. Theory of Reasoned Action [23,26,40] The formation of intentions precedes and predicts behavior, and that intentions are determined by attitudes towards the behavior and subjective norms concerning the behavior [3].

42. Transtheoretical Stages of Change Model $[24,26,28,40]$ Intentional change is a gradual movement through specific but non-linear stages, from not intending to change to sustaining change. Interventions should be tailored to the motivational stage an individual has reached $[6,7]$.

\section{REFERENCES}

1. Nicklas TA, Webber LS, Johnson CC, Srinivasan SR, Berenson G. Foundations for health promotion with youth: A review of observations from the Bogalusa Heart Study. J Health Educ 1995;10:S18-26.

2. Walker AE, Grimshaw J, Johnston M, Pitts N, Steen N, Eccles M. PRIME-Process modelling in ImpleMEntation research: selecting a theoretical basis for interventions to change clinical practice. BMC Health Serv Res 2003;3:22.

3. Horne R,Weinman J. Predicting treatment adherence: An overview of theoretical models. In: Myers LB, Midence K, editors. Adherence to Treatment in Medical Conditions. Amsterdam: Harwood Academic Publishers; 1998. p. 25-50.

4. Revere $D$, Dunbar J. Review of computer-generated outpatient health behavior interventions: clinical encounters "in Absentia". J Am Med Inform Assoc 2001;8:62-79.

5. Becker MH, Maiman LA, Kirscht JP, Haefner DP, Drachman RH, Taylor DW. Patient perceptions and compliance: recent studies of the Health Belief Model. In: Haynes RB, Sackett DL, Taylor DW, editors. Compliance in Healthcare. Baltimore: John Hopkins University Press; 1979. p. 78-109.

6. Prochaska JO, DiClemente CC. The transtheoretical approach. In: Norcross JC, editor. Handbook of Psychotherapy Integration. New York, NY, USA: Basicbooks Inc.; 1992. p. 30034.

7. Prochaska JO, Redding CA, Harlow LL, Rossi JS, Velicer WF. The transtheoretical model of change and HIV prevention: a review. Health Educ Q 1994;21:471-86.

8. Bandura A. Social cognitive theory of self-regulation. Organizational Behav Hum Decis Processes 1991;50:248-87.

9. Cole M, Cole SR. The Development of Children. 2nd ed. New York: Scientific American Books; 1993.

10. Bibace R, Walsh ME. Development of children's concepts of illness. Pediatrics 1980;66:9127.

11. van Dulmen AM. Patient-centredness. Patient Educ Couns 2003;51:195-6 (Editorial).

12. Tates K, Theunissen NCM. Models and theories in studies on educating and counseling adolescents about physical health: a systematic review, in preparation.

13. Stevens J, Story M, Ring K, Murray DM, Cornell CE, Juhaeri. Gittelsohn J. The impact of the Pathways intervention on psychosocial variables related to diet and physical activity in American-Indian schoolchildren. Prev Med 2003;37:S70-9.

14. levers-Landis CE, Burant C, Drotar D, Morgan L, Trapl ES, Kwoh CK. Social support, knowledge, and self-efficacy as correlates of osteoporosis preventive behaviors among preadolescent females. J Pediatr Psychol 2003;28:335-45.

15. Moody KA, Childs JC, Sepples SB. Intervening with at-risk youth: evaluation of the youth empowerment and support program. Pediatr Nurs 2003;29:263-70.

16. Finke L, Williams J, Ritter M, Kemper D, Kersey S, Nightenhauser J, Autry K, Going C, Wulfman G, Hail A. Survival against drugs: education for school-age children. J Child Adolesc Psychiatr Nurs 2002;15:163-9.

17. Burnet $\mathrm{D}$, Plaut $\mathrm{A}$, Courtney $\mathrm{R}$, Chin $\mathrm{MH}$. A practical model for preventing type 2 diabetes in minority youth. Diabetes Educ 2002;28:779-95.

18. Schonfeld DJ, Bases H, Quackenbush M, Mayne S, Morra M, Cicchetti D. Pilot-testing a cancer education curriculum for grades K-6. J Sch Health 2001;71:61-5. 
19. Horn K, Kolbo JR. Application of a cumulative strategies model for drug abuse prevention: exploring choices for high risk children. J Drug Educ 2000;30:291-312.

20. Stanken BA. Promoting helmet use among children. J Community Health Nurs 2000;17:8592.

21. Baranowski T, Davis M, Resnicow K, Baranowski J, Doyle C, Lin LS, Smith M, Wang DT. Gimme 5 fruit, juice, and vegetables for fun and health: outcome evaluation. Health Educ Behav 2000;27:96-111.

22. Fitzpatrick KM. Fighting among America's youth: a risk and protective factors approach. J Health Soc Behav 1997;38:131-48.

23. Aarts $\mathrm{H}$, Paulussen $\mathrm{T}$, Schaalma $\mathrm{H}$. Physical exercise habit: On the conceptualization and formation of habitual health behaviours. Health Educ Res 1997;12:363-74.

24. Baranowski T, Hearn MD. Health behavor interventions with families. In: Handbook of health behavior research. Gochman DS, editor. Relevance for Professionals and Issues for the Future, Vol.4. New York, NY, US: Plenum Press; 1997. p. 303-23.

25. Lerner RM, Ostrom CW, Freel MA. Preventing health-compromising behaviors among youth and promoting their positive development: A developmental contextual perspective. In: Schulenberg J, Maggs JL, editors. Health Risk and Developmental Transitions During Adolescence. New York, NY, USA: Cambridge University Press; 1997 . p. 498-521.

26. Craig S, Goldberg J, Dietz WH. Psychosocial correlates of physical activity among fifth and eighth graders. Prev Med 1996;25:506-13.

27. Spoth R, Redmond C, Hockaday C, Yoo S. Protective factors and young adolescent tendency to abstain from alcohol use: A model using two waves of intervention study data. Am J Community Psychol 1996;24:749-70.

28. Rossi JS, Blais LM, Redding CA, Weinstock MA. Preventing skin cancer through behavior change. Implications for interventions. Dermatol Clin 1995;13:613-22.

29. Santi SM, Cargo M, Brown KS, Best JA, Cameron R. Dispositional risk factors for smokingstage transitions: a social influences program as an effect modifier. Addict Behav 1994;19:269-85.

30. Livingston IL. Stress, hypertension, and young Black Americans: The importance of counseling. J Multicult Couns Dev 1993;21: 132-42.

31. Claar RL, Walker LS, Smith CA. The influence of appraisals in understanding children's experiences with medical procedures. J Pediatr Psychol 2002;27:553-63.

32. Whaley BB. Explaining illness to children: theory, strategies, and future inquiry. In: Whaley BB, editor. Explaining Illness: Research, Theory, and Strategies. London: Lawrence Erlbaum Associates; 2000. p. 195-208.

33. Rushforth $\mathrm{H}$. Practitioner review: communicating with hospitalised children: review and application of research pertaining to children's understanding of health and illness. J Child Psychol Psychiatry 1999;40:683-91.

34. Whaley BB. Explaining illness to children: Advancing theory and research by determining message content. Health Commun 1999;11:185-93.

35. Whitener LM, Cox KR, Maglich SA. Use of theory to guide nurses in the design of health messages for children. Adv Nurs Sci 1998;20:21- 35.

36. Maieron MJ, Roberts MC, Prentice-Dunn S. Children's perceptions of peers with AIDS: assessing the impact of contagion information, perceived similarity, and illness conceptualization. J Pediatr Psychol 1996;21:321-33.

37. Tinsley BJ, Holtgrave DR, Reise SP, Erdley C, Cupp RG. Developmental status, gender, age, and self-reported decision-making influences on students' risky and preventive health behaviors. Health Educ Q 1995;22:244-59.

38. Campbell LA, Kirkpatrick SE, Berry CC, Lamberti JJ. Preparing children with congenital heart disease for cardiac surgery. J Pediatr Psychol 1995;20:313-28.

39. Biddinger LA. Bruner's theory of instruction and preprocedural anxiety in the pediatric population. Issues Compr Pediatr Nurs 1993;16:147-54.

40. Clark NM, Valerio MA. The role of behavioural theories in educational interventions for paediatric asthma. Paediatr Respir Rev 2003;4:325-33.

41. Tieffenberg JA, Wood El, Alonso A, Tossutti MS, Vicente MF. A randomized field trial of ACINDES: a child-centered training model for children with chronic illnesses (asthma and epilepsy). J Urban Health 2000;77:280-97.

42. Bartholomew LK, Gold RS, Parcel GS, Czyzewski DI, Sockrider MM, Fernandez M, Shegog R, Swank P. Watch, Discover, Think, and Act: evaluation of computer-assisted instruction to improve asthma selfmanagement in inner-city children. Patient Educ Couns 2000;39:269- 80. 
Theunissen, N.C.M., Tates, K.

Models and theories in studies on educating and counseling children about physical health: a systematic review.

Patient Education and Counseling: 55, 2004, nr. 3, p. 316-330

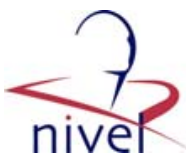

43. McGhan SL, Wells HM, Befus AD. The "Roaring Adventures of Puff": a childhood asthma education program. J Pediatr Health Care 1998;12:191-5.

44. Richardson RC. Discipline and children with chronic illnesses: strategies to promote positive patient outcomes. ANNA J 1997;24: 35-40.

45. Bartholomew LK, Koenning G, Dahlquist L, Barron K. An educational needs assessment of children with juvenile rheumatoid arthritis. Arthritis Care Res 1994;7:136-43.

46. Parcel GS, Swank PR, Mariotto MJ, Bartholomew LK, Czyzewski DI, Sockrider MM, Seilheimer DK. Self-management of cystic fibrosis: a structural model for educational and behavioral variables. Soc Sci Med 1994;38:1307-15.

47. Lieberman DA. Management of chronic pediatric diseases with interactive health games: theory and research findings. J Ambul Care Manage 2001;24:26-38.

48. Schwarzer R, Fuchs R. Self-efficacy and health behaviours. In: Conner M, Norman P, editors. Predicting Health Behaviour: Research and Practice With Social Cognition Models. Buckingham: Open University Press; 1996. p. 163-96.

49. Bartholomew LK, Shegog R, Parcel GS, Gold RS, Fernandez M, Czyzewski DI, Sockrider MM, Berlin N. Watch, discover, think, and act: a model for patient education program development. Patient Educ Couns 2000;39:253-68.

50. Rylance G. Making decisions with children. Br Med J 1996;312: 794.

51. Hart C, Chesson R. Children as consumers. Br Med J 1998;316: 1600-3.

52. de-Winter M, Baerveldt C, Kooistra J. Enabling children: participation as a new perspective on childhealth promotion. Child Care Health Dev 1999;25:15-25.

53. Tapias MA, De Miguel G, Jimenez-Garcia R, Gonzalez A, Dominguez V. Incidence of caries in an infant population in Mostoles, Madrid. Evaluation of a preventive program after 7.5 years of follow-up. Int J Paediatr Dent 2001;11:440-6. JID-9107511.

54. Dixon-Woods M, Young B, Heney D. Partnerships with children. Br Med J 1999;319:778-80.

55. Scott J. Children as respondents. The challenge for quantitative methods. In: Christensen $P$, James A, editors. Research With Children. Perspectives and Practices. London: Falmer Press; 2000. p. 98-119.

56. Lightfoot J, Sloper P. Having a say in health: involving young people with a chronic illness or physical disability in local health services development. Children Soc 2004;17:277-90.

57. Leventhal H, Nerenz DR, Steele DJ. Illness representations and coping with health threats. In: Handbook of Psychology and Health. Hillsdale, New Jersey: Lawrence Erlbaum Associates; 1984.

58. Bozionelos G, Bennett $P$. The theory of planned behaviour as predictor of exercise: The moderating influence of beliefs and personality variables. J Health Psychol 1999;4:517-29.

59. Lien N, Lytle LA, Komro KA. Applying theory of planned behavior to fruit and vegetable consumption of young adolescents. Am J Health Promot 2002;16:189-97. 